\title{
DEMANDAS ELEITORAIS: ESTABILIZAÇÃO, FATOS NOVOS E DECADÊNCIA
}

Electoral demands: stabilization, new facts and decay term

\section{Luiz Fernando Casagrande Pereira}

Resumo: O Direito Eleitoral, no mundo inteiro, tem prazos decadenciais rígidos para a propositura das ações eleitorais, assim como está na Constituição brasileira (art. 14, \10²). Trata-se de pressuposto elementar da estabilidade jurídica do mandato. Estes prazos decadenciais não podem ser subvertidos a partir da extemporânea ampliação objetiva de demandas eleitorais em trâmite. Noutras palavras, fatos novos (novas causas de pedir) não autorizam novas ações fora do prazo decadencial e, pelas mesmas razões, não podem ser incluídos em ações em curso.

Palavras-chave: Ações eleitorais. Fatos novos. Prazos de decadência. Estabilidade de mandatos.

\begin{abstract}
All over the world, the electoral law has very short expiring deadlines for the proposition of electoral actions, as it can be observed in the Brazilian Constitution (art. 14, $\left.\int 10^{\circ}\right)$. This is a basic assumption of the legal stability of political mandates. These expiring deadlines cannot be overturned by the untimely objective growth of ongoing electoral demands. In other words: new facts (new requests) do not authorize new actions after the expiring deadline and, for the same reasons, cannot be included in ongoing actions.
\end{abstract}

Keywords: Electoral demands. New facts. Decay term. Stabilization of the mandates.

Artigo recebido em 2 jun. 2017 e aprovado em 9 nov. 2018. 


\section{Ações eleitorais e prazos decadenciais. Estabilidade da democracia. A clara opção do constituinte, alinhada ao direito comparado}

A Constituição estabeleceu um limite rígido para a sindicabilidade judicial dos mandatos eletivos: 15 dias depois da diplomação (art. 14, \10%). A lei e a jurisprudência (inspirada sempre no prazo limite da Constituição) também definiram prazos decadenciais curtos para: a ação de investigação judicial eleitoral (AIJE), art. 22 da Lei no 64/1990; o recurso contra expedição de diploma (RCED), art. 262 do Código Eleitoral; e as representações eleitorais da Lei no 9.504/1997. Sempre há curtos e rígidos prazos decadenciais por disposições legais ou construção jurisprudencial (à luz do próprio limite da $\mathrm{CF}$ ). Prazos exíguos para a propositura de ações eleitorais estão previstos na legislação brasileira desde o Código Eleitoral de 1932 (Decreto $\mathrm{n}^{\mathrm{o}}$ 21.076, de 24 de fevereiro de 1932).

Como fundamenta a doutrina, "a fixação de um determinado lapso temporal dentro do qual poderá o legitimado infirmar a vontade popular é imperativo de ordem pública, imprescindível à paz social" (GARCIA, 2000, p. 188-191). O vetor que orienta a disposição de prazos decadenciais exíguos, reconhece a doutrina portuguesa, é "a própria segurança do estado de Direito Representativo e Democrático” (AMADO, 1994).

A opção do constituinte brasileiro foi objeto de lúcida ponderação. A ideia original do Projeto de Constituição da Comissão de Notáveis previa um prazo de até seis meses, a partir da diplomação, para se impugnar um mandato. Durante os debates foi cogitado até mesmo o prazo decadencial de dois anos para a ação judicial desconstitutiva de mandato (SANTOS, 1998). Ao final, restou prestigiada a segurança jurídica dos mandatos - importante para a estabilidade da democracia -, com a definição do curto prazo de 15 dias para a AIME (a orientar todos os demais prazos decadenciais para as ações de cassação).

A Constituição brasileira, portanto, fez uma nítida opção por um exíguo prazo limite para impugnar mandatos eletivos. A opção brasileira - e os motivos dessa opção - amparam-se em um consenso da legislação comparada: a democracia não convive bem com a instabilidade dos mandatos. E a instabilidade está, sobretudo, em prazos excessivamente longos para o controle de legitimidade (judicial ou administrativo) das eleições. 
Em relação à América Latina, a orientação é sempre por prazos curtos e pelos mesmos fundamentos. Como está para um eleitoralista latino-americano, a decadência protege o interesse geral em uma certificação rápida do processo eleitoral (ESPINOSA apud HERNÁNDEZ, 2010). Na Colômbia, os prazos decadenciais estão fixados em até 20 dias depois do resultado (SERRANO, 2014), e a doutrina os considera compatíveis com a Constituição (citando precedentes da Corte Constitucional) porque o processo eleitoral não pode ficar incerto indefinidamente, sob pena de violar o princípio da segurança jurídica (importante para eleitores e eleitos - para democracia, enfim) ${ }^{1}$. É decisivo entregar celeremente a certeza da legitimidade para os eleitos (MESSINEO, 1971).

Ainda na América Latina, os mexicanos condicionam a impugnação em matéria eleitoral à apresentação em até quatro dias do resultado ${ }^{2}$. Já a doutrina argentina, ao tratar dos meios de impugnação de mandato, destaca a existência de prazos "exíguos, improrrogáveis e essencialmente preclusivos” (PÉREZ CORTI, 2009). A Costa Rica, por sua vez, limita em três dias o prazo para impugnar resultados (MÉXICO, 2006). Os uruguaios tinham prazos mais amplos, mas reformaram a legislação para estipular em três dias o termo final para impugnar a eleição (URUGUAY, 1999). A verdade é que, em toda a América Latina, tal processo é semelhante (OROZCO apud NOHLEN et al., 2007).

Os exemplos colhidos na Europa não são diferentes. Os portugueses reconhecem a necessidade de "tornar pacífica a atribuição do mandato ao seu titular o mais rápido possível”. Por essa razão, “as irregularidades não questionadas no momento oportuno deixam de ser passíveis de apreciação e julgamento" (PERREIRA, 2008). A situação política não pode ficar em um limbo, anota a autora portuguesa (AMADO, 1994). $\mathrm{Na}$

\footnotetext{
${ }^{1}$ LUIS, Díez-Picazo. La prescripción em el código civil. Barcelona: Bosh Casa Editorial,p. 55-57. In: ESPINOSA, Armando Cruz. Aspectos básicos del proceso electoral. In: HERNÁNDEZ, Eduardo de Jesús Castellanos (org). Temas de derecho procesal electoral. México: Segob, 2010, p. 180.

${ }^{2}$ Artículo 8: 1. Los medios de impugnación previstos en esta ley deberán presentarse dentro de los cuatro días contados a partir del día siguiente a aquél en que se tenga conocimiento del acto o resolución impugnado, o se hubiese notificado de conformidad con la ley aplicable, salvo las excepciones previstas expresamente en el presente ordenamiento.
} 
Alemanha, o prazo limite é de 30 dias. Os espanhóis consideram acatado o resultado se não houver o imediato questionamento deste ${ }^{3}$.

Em estudo realizado pela Comissão Eleitoral do Reino Unido, foram levantados diversos dados acerca do prazo para contestar o resultado das eleições em alguns países da Europa (UNITED KINGDON, 2012). Especificamente no Reino Unido (berço do controle jurisdicional), as petições devem ser apresentadas em até 28 dias após o resultado das eleições para apurar práticas eleitorais corruptas. Em todo o continente, os prazos são curtíssimos: três dias em países como Estônia, Letônia, Malta e Suíça; 10 dias em França, Suécia, República Checa e Eslováquia; 25 dias na Grécia; 28 na Áustria; até um mês na Bulgária e em Chipre; dois meses na Alemanha (EUROPEAN..., 2009). A legislação eleitoral italiana, por fim, prevê 30 dias como limite para impugnar mandatos (DÍAZ VÁSQUEZ, 1993).

A própria Comissão Europeia para a Democracia Através do Direito (Comissão de Veneza) já consignou que os prazos devem ser exíguos para não dificultar o funcionamento da democracia (EUROPEAN..., 2009).

A opção brasileira, portanto, está devidamente orientada pela mesma racionalidade dos sistemas de controle de legitimidade eleitoral do direito comparado. Todos os autores que escreveram sobre o tema reconhecem que o vetor principal de prazos decadenciais exíguos é a estabilidade da democra$\mathrm{cia}^{4}$. O prazo decadencial, enfim, inspira-se em um "postulado de segurança jurídica, de normalidade e de harmonia das instituições” (BARBOSA, 1992).

Transpor (ainda que por via oblíqua) um prazo decadencial viola a Constituição Federal e a própria racionalidade subjacente: a estabilidade da democracia.

3 "La falta de reclamación oportuna 'es tanto como aquietar-se o consentir la decisión adoptada, por lo que se priva al dissidente con tal decisión de poder acudir posteriormente al recurso contencioso electoral' [...] la no interposición del recurso electoral 'supone um acatamiento total al recultado consagrado com tal proclamación”’. In: DELGADO, Manuel Gil. Las garantias del derecho electoral. Revista de las Cortes Generales, n. 7, p. 109, 1990. ${ }^{4}$ BARBOSA, Edmilson. Ação de Impugnação ao Mandato Eletivo (AIME). p. 9. Disponível em: <http://esmec.tjce.jus.br/wp-content/uploads/2008/10/acao-de-impugnacao-ao-mandato-eletivo.pdf $>$. Acesso em: 29 mar. 2017; MENDES, Antonio Carlos. Introdução à teoria das inelegibilidades. São Paulo: Malheiros, 1994. p. 154-155; SILVA, Daniel Monteiro. Ação de impugnação de mandato eletivo: análise constitucional e novas perspectivas. 185 f. Dissertação (Mestrado em Constituição e Garantias de Direitos) - Universidade Federal do Rio Grande do Norte. Natal: 2010. p. 137; FICHTNER, José Antônio. Impugnação de mandato eletivo. Rio de Janeiro: Renovar, 1998. p. 81; GARCIA, Emerson. Ação de impugnação de mandato eletivo. Rio de Janeiro: Lumen Juris, 2000. p. 188-191. 


\section{A regra de estabilização da demanda no Direito Eleitoral. Fatos essenciais a compor a causa de pedir. Impossibilidade de julgamento extra petita}

De forma sinóptica, considerando o NCPC, doutrina e jurisprudência majoritárias (inclusive do TSE), a parte tem a faculdade de alterar a causa de pedir e o pedido (NCPC, art. 319, inc. III). Nesse caso, o NCPC (tal como o CPC) delimita prazos: (i) até a citação (NCPC, art. $231 \mathrm{c} / \mathrm{c}$ art. 329 , inc. I) - porque ainda não conformada a relação processual —, poderá existir modificação do pedido ou da causa de pedir, sem necessidade do consentimento da outra parte; (ii) após a citação (NCPC, art. 231 e art. 329 , inc. II) — já conformada a relação processual —, apenas com a anuência (comissiva ou omissiva) do réu. Depois do saneamento, nem mesmo com o consentimento da outra parte. Fora disso, já definidos os contornos objetivos da demanda, há regras em torno dos fatos supervenientes e/ou de conhecimento superveniente (NCPC, art. 493). Necessário entender as hipóteses possíveis para a inclusão de fatos novos.

Importante, antes disso, ter em consideração que nenhuma demanda eleitoral pode ser proposta sem o ínsito preenchimento do suporte fático. Não se propõe uma demanda eleitoral com narrativa fática vazia ou lacônica, apenas enunciando a categorização jurídica (art. 30-A; abuso, etc.). Não podem ser admitidas alegações genéricas (AMBRIZI, 2014). A inicial não pode se fundar apenas na moldura do fato (dinheiro de "caixa dois"), mas em um fato que aceite (em tese) a subsunção a "caixa dois" (art. 30-A). Não se admite uma substanciação extemporânea; uma ação eleitoral em branco, no prazo decadencial, para depois ser preenchida (substanciada) em um aleatório porvir, sem prazo para ser revelado.

É imprescindível "a descrição clara e precisa do acontecimento que foi a razão de ser da demanda" (VIANA apud CRUZ E TUCCI; BEDAQUE, 2002). A causa de pedir pressupõe uma delimitação exata do fato. Trata-se de exigência mínima da petição inicial (art. 319, II, NCPC). Devem ser indicados, enfim, todos os elementos da causa de pedir remota. Assim a demanda eleitoral se estabiliza.

Importante ter em conta que "a matéria da estabilização da demanda guarda forte relação com o tema da causa petendi” (PINTO, 2007). Como está para a melhor doutrina "qualquer tentativa de modificação do núcleo fático em que se funda a demanda, corresponde ao inválido exercí- 
cio ex novo de um poder de ação diverso daquele verificado na instauração do processo" (CRUZ E TUCCI, 2009). A partir da leitura predominante da regra de estabilização da demanda, está desautorizada a modificação do núcleo fático das demandas eleitorais, especialmente em matéria de cassação.

Não se trata - merece nota - de uma simples reverência fetichista ao formalismo. O respeito à estabilização da demanda liga-se a dois vetores do processo civil: garantia do contraditório e da celeridade (tão cara ao direito processual eleitoral). E, no Direito Eleitoral, tem ainda a necessidade de respeitar o prazo decadencial. A eventual metamorfose de objeto fulmina o contraditório, compromete a celeridade e subverte o prazo decadencial. Antes disso, é regra expressa do NCPC (art. 329, II) e orientação do TSE. A norma cogente determina a imutabilidade do objeto.

Toda a jurisprudência, inclusive a eleitoral, rejeita o julgamento fora dos limites delineados na inicial: o juiz decidirá a lide nos limites em que foi proposta, sendo-lhe defeso conhecer de questões não suscitadas, cujo respeito à lei exige a iniciativa da parte. Desse modo, é vedado ao magistrado decidir com base em fatos não constantes da petição inicial. (Recurso Especial Eleitoral no 428765026, Rel. Min. JOSÉ ANTÔNIO DIAS TOFFOLI, 10/03/2014).

Desprezar o argumento é dar ensejo a um nítido vício de extrapetição. A sentença extra petita é flagrada por ultrapassar, indistintamente, o pedido ou a causa de pedir (VIEIRA, 2012) ${ }^{5}$. Enfim, admitir o julgamento a partir de causas de pedir tardiamente reveladas de ofício, é decidir extra petita, eivando de nulidade a decisão (WAMBIER, 1996. Se a causa de pedir é distinta, distinto é o pedido (a causa de pedir conforma o pedido) (DIDIER, 2012) ${ }^{6}$. Todas essas questões relacionadas à estabilização da demanda ganham mais atenção no direito eleitoral quando conjugadas aos prazos decadenciais rígidos.

\footnotetext{
${ }^{5}$ Também poderá ser extra petita em relação à causa de pedir, contemplando fato diverso daquele que compôs a causa petendi remota. Nessa hipótese, o julgamento de situação fática diversa da narrada na inicial fatalmente implicará em julgamento de pedido diferente, já que o pedido decorre da causa de pedir.

${ }^{6}$ Fredie Didier explica que, se a causa de pedir é distinta, distinto também é o pedido que se deduz a partir desta causa de pedir: "Não se pode considerar igual aquilo que é diferente (princípio lógico da não contradição): se os atos impugnados são distintos, distintos também são os pedidos".
} 


\section{A admissão de fatos novos (art. 493, NCPC) não pode deformar ou reconfigurar o objeto original. A instrução não é instrumento de mutação do objeto. Apenas os fatos simples - jamais os essenciais - podem ser admitidos}

$\mathrm{O}$ art. 493 autoriza tomar em consideração fatos novos (supervenientes ou de conhecimento superveniente $)^{7}$ que possam influir no julgamento. O dispositivo, no entanto, não derroga a regra da estabilização da demanda. Cassio Scarpinella Bueno explica a compatibilidade do dispositivo com a regra de estabilização: "[...] são apenas os fatos simples, isto é, que não têm aptidão de alterar a causa de pedir, mas, apenas e tão somente, de prová-la, confirmá-la e delimitá-la" (SCARPINELLA BUENO apud MARCATO, 2004) ${ }^{8}$. Não se admite "fato novo estranho à causa petendi e que constitua fundamento suficiente para nova demanda". É assim também para o STJ ${ }^{9}$.

Os fatos simples apenas "se prestam a precisar, descrever ou comprovar" os fatos essenciais que já compunham a causa de pedir deduzida ao início (SCARPINELLA BUENO apud MARCATO, 2004). Os fatos novos de conhecimento superveniente são fatos constitutivos que fundamentariam uma pretensão autônoma de cassação (DEGENSZAJN, 2010) ${ }^{10}$. São fatos jurídicos: fatos principais; fatos-título; fatos essenciais (AMBRIZI, 2014). Tais fatos alteram a causa de pedir e, por isso, é inadmissível a inclusão tardia por violação da regra de estabilização da demanda.

Na linha do STJ - como está no precedente do Ministro FUX citado adiante -, assim também entendeu o Regional Eleitoral de São Paulo,

\footnotetext{
${ }^{7}$ Fatos supervenientes ou de conhecimento superveniente têm a consequência.

${ }^{8}$ Para conferir a lista de autores com esta posição: CUNHA, Leonardo Carneiro da. In: WAMBIER, Teresa Arruda Alvim; DIDIER JUNIOR, Fredie; TALAMINI, Eduardo, DANTAS, Bruno. Breves comentários ao novo código de processo civil. São Paulo: Editora RT, 2015. p. 1.246. Em sentido oposto, admitindo a alteração, LEONEL, Ricardo Barros. Causa de pedir e pedido: o direito superveniente. São Paulo: Método, 2006. p. 259-263.

9 " $\mathrm{O}$ fato superveniente a ser considerado pelo julgador deve guardar pertinência com a causa de pedir e pedido constantes na inicial, não servindo de fundamento para alterar os limites da demanda fixados após a estabilização da lide" (AgInt no REsp 1169783/GO, Rel. Min. RAUL ARAÚJO, 20/10/2016).

${ }^{10}$ Sobre a diferença entre fatos simples e essenciais, VESCOVI, Enrique. La modificación de la demanda. Revista de Processo, v. 8, n. 30, p. 206-2012, abr./jun., 1986.
} 
aqui em acórdão de um dos mais conceituados processualistas brasileiros, ex-Juiz do TRE-SP, Flávio YARSHELL: "Os fatos supervenientes, em que pesem devam ser levados em conta por ocasião de julgamento, não podem implicar alteração da causa de pedir [...] para que sejam observados também o contraditório e a regra da estabilização da demanda"11.

No acórdão, o Relator, Flávio Yarshell, recusa-se incluir na causa fatos não contidos no objeto original, com a seguinte fundamentação: "não se trata simplesmente de prova dos fatos alegados na representação, mas de elementos indicativos de outros fatos - quiçá constitutivos de outra pretensão". E complementa: "é cediço que fatos supervenientes, conquanto devam ser levados em conta por ocasião do julgamento (CPC, art. 462), não podem implicar em alteração da causa de pedir”, especialmente, concluiu, para a "preservação da regra de estabilização da demanda"12.

No precedente do Ministro Luiz Fux, hoje, também no TSE, reitera-se: "A superveniência de fato ou direito que possa influir no julgamento da lide deve ser considerada pelo julgador, desde que não importe em alteração do pedido ou da causa de pedir"'13. Agora é pertinente avaliar o tema da decadência.

\section{A flexibilização da regra de estabilização, minoritária em doutrina e jurisprudência, é incogitável no direito eleitoral em atenção à rigidez do prazo decadencial}

Atualmente, é verdade, há uma corrente minoritária que reconhece a necessidade de certa mitigação da imutabilidade dos elementos subjetivos e objetivos da demanda. Para essa parcela da doutrina "pode ocorrer que, em determinadas situações, sobretudo no momento da produção da prova, surja um fato novo, que conduza à mesma consequência jurídica pretendida pelo demandante" (CRUZ E TUCCI, 2009). Nesses casos, ex-

\footnotetext{
11 TRE-SP, RC no 26851, Rel. Flávio Luiz Yarshell, julgado em 31/07/2008.

${ }^{12}$ A doutrina é unânime: "é aquele estreitamente vinculado à lide posta à apreciação, levando em conta a causa de pedir já deduzida, não podendo, por conseguinte, ser considerado para a decisão da lide fato novo estranho à causa petendi e que constitua fundamento suficiente para nova demanda" (PORTO, ANO, p. 127). Cf. ainda: PINTO JUNIOR (2014). Também no mesmo sentido: COSTA (2002); DINAMARCO (2004, p. 283-284).

${ }^{13}$ STJ. AgRg no REsp 1.116.836/MG, 1. a T., j. 05.10.2010, rel. Min. Luiz Fux, DJe18.10.2010.
} 
cepcionalmente, admitir-se-ia esta ampliação tardia dos elementos objetivos da demanda, desde que assegurado o contraditório ${ }^{14}$.

O tópico antecedente revelou que se trata de corrente minoritária em doutrina e sem amparo na orientação da jurisprudência. O STJ e o TSE, em inúmeros precedentes, não admitem a mutação tardia do objeto litigioso.

E, a se admitir a chamada flexibilização da regra de estabilização da demanda, especificamente em Direito Eleitoral, as ampliações subjetiva e objetiva da demanda encontrarão um limite nítido e intransponível: o prazo decadencial, tão caro à estabilidade da democracia, aqui no Brasil e nos regimes democráticos do mundo inteiro. É dizer: a ampliação não poderia ocorrer se já esgotado o prazo decadencial.

A flexibilização nada mais é do que a permissão de alteração do núcleo fático por uma técnica de economia processual, evitando a propositura de uma nova demanda autônoma (BEDAQUE, 2006). Se fatos novos, por exemplo, forem sido colhidos no ambiente de uma AIJE já estabilizada, negada a flexibilização, os autores poderiam propor outra demanda, que seria reunida por conexão à preexistente (novo art. 96-B da Lei Eleitoral).

Por isso há certa inocuidade no debate em torno da ampliação. Rejeitar a ampliação tardia do objeto sempre se resolve na propositura de ação conexa, com a reunião dos processos. Trata-se do mesmo raciocínio que conduz à admissão de litisconsórcio ulterior com aditamento do pedido. Nos dois casos, alcança-se a ampliação (objetiva e subjetiva) por via transversa ${ }^{15}$.

A decadência, no entanto, é um limite insuperável.

Muitas vezes, os fatos novos surgem quando há outra ação em curso, com objeto distinto. No entanto, se ações em curso não guardarem correspondência com os novos fatos essenciais revelados, estes não podem ser admitidos. A existência de uma ação "01" (causas de pedir “a. b. c”) não pode ser via transversa para a propositura de uma ação " 02 ” (causa de pedir “d.e.f”) que já esteja fulminada pelo prazo decadencial. A ação “02” não pode ser enxertada na "01” para burlar o prazo decadencial.

É singelo, mas incontornável.

\footnotetext{
${ }^{14}$ Sobre o tema, em especial, a monografia de LEONEL, op. cit., p. 242-250.

${ }^{15}$ A ideia e o exemplo são de LEONEL, op. cit., p. 247-249.
} 
Daniel Raichelis Degenszajn, autor de inovadora tese de Doutorado na USP sob a flexibilização da regra de estabilização (orientando de DINAMARCO), defende a possibilidade de introdução de causa de pedir nova, mas destaca o limite óbvio: "É claro que o pedido de introdução de causa nova deverá ser apresentado ainda dentro do prazo decadencial, sob pena de se considerar um prazo não querido pelo legislador" (DEGENSZAJN, 2010).

É precisamente por esta razão que o TSE, após o prazo decadencial próprio, não admite em nenhuma hipótese a ampliação subjetiva da demanda (inclusão de litisconsorte) ${ }^{16}$. E, se inadmissível a ampliação subjetiva, com mais razão não se pode acolher a ampliação objetiva depois de decorrido o prazo decadencial máximo (a ratio do precedente é perfeitamente aplicável nos dois sentidos).

É como julga também o Superior Tribunal de Justiça. Tanto quanto a AIME, o mandado de segurança tem prazo decadencial. Por essa razão, decorrido o prazo de 120 dias, o STJ não admite emenda à inicial do mandamus, com ampliação objetiva, "por implicar subversão do prazo decadencial" "17. Mesma orientação no STJ para as rescisórias. Decorrido o prazo decadencial para propositura de rescisória, a ação não pode ser proposta contra novo réu, sendo impossível a regularização processual em tal momento $^{18}$. Seria o mesmo que admitir nova inicial fora do prazo, reconhecem os tribunais ${ }^{19}$.

16 "Não merece guarida a argumentação de que não foi concedida oportunidade de promover a citação do litisconsorte, nos termos do parágrafo único do art. 47 do CPC, porquanto tal providência seria inviável nesta via processual, pois já escoado o prazo decadencial para a propositura da demanda”. (TSE. Agravo Regimental em Recurso Especial Eleitoral no 145082, Rel. Min. GILMAR MENDES, 05/03/2015). A doutrina também aponta o óbice da decadência para a ampliação: "A não constituição do litisconsórcio passivo necessário no prazo legal faz com que se opere a decadência do direito, impondo-se a extinção do processo" (GOMES, 2016, p. 800). No mesmo sentido: FICHTNER (1998, p. 83); NIESS (2000, p. 294); e ALVIM (2011).

${ }^{17}$ STJ. EDcl no MS 13.825/DF, Rel. Ministro Benedito Gonçalves, j. 05/03/2009.

${ }^{18}$ STJ. REsp 863.890/SC. Rel. Ministra Nancy Andrighi, j. 28/02/2011.

19 "Revela manifesta burla ao regime processual da ação rescisória a apresentação de aditamento da inicial da ação rescisória, quando já ultimado o prazo decadencial, no qual, a título de aditamento, é alterada toda a substância da causa de pedir outrora deduzida. Acaso seja tomado esse aditamento como parte integrante da inicial, estar-se-á a admitir nova petição inicial oferecida quando já transcorrido o prazo decadencial, o que não é possível" 
Ações em curso, enfim, não podem ser veículo disponível a abrigar fatos novos ou fatos de conhecimento superveniente que não poderiam amparar extemporânea ação autônoma. Na linguagem do STJ, não se pode subverter o prazo decadencial. Em Direito Eleitoral, essa vedação tem especial significado: a estabilidade da democracia.

\section{A livre apreciação dos fatos não derroga o princípio dispositivo e muito menos o prazo decadencial. A instrução de ofício também não pode conformar novas demandas}

É importante advertir que o art. 23 da LC n⿳0 64/1990 não altera em nada o raciocínio desenvolvido até aqui. Inicialmente porque o dispositivo não derroga a regra de estabilização da demanda. O maior protagonismo para o juiz eleitoral participar da formação da prova não autoriza a introdução, de ofício, de novas causas de $\operatorname{pedir}^{20}$. E, se estivesse autorizada esta ampliação de ofício, evidentemente o prazo decadencial seguiria sendo um óbice instransponível à admissão dos noticiados novos fatos.

Enfim, o controvertido art. 23, incompatível com o NCPC para muitos (a ADI no STF foi julgada à luz do CPC/1973), no máximo, diz apenas com certo ativismo probatório ${ }^{21}$. No entanto, este ativismo probatório desautoriza um garimpo por novas causas de pedir não deduzidas na demanda, como reconhece a jurisprudência eleitoral ${ }^{22}$.

(TJ-DF - AGR1: 20140020054649 DF 0005495-68.2014.8.07.0000, Rel.: Simone Lucindo, $1^{\text {a }}$ Câmara Cível, 23/04/2014).

20 “A jurisdição não é uma atividade espontânea, mas provocada (nemo iudex sine actore), e, pela mesma razão de ser incoada por iniciativa do interessado, como uma atividade devida pelo Estado-juiz, é que ela deverá ser prestada de acordo e na medida em que foi pedida, efetuando-se precisamente sobre aquele direito afirmado, e não de outro”. (COSTA, 2002).

${ }^{21}$ GOMES (2012, p. 58-59). Sobre a crítica doutrinária ao art. 23, vale conferir SALGADO; VALIATI; BENARDELLI (apud TAVARES et al., 2016, p. 355-357).

22 "A estabilização da demanda não pode estar condicionada a uma atuação do juiz no sentido de 'garimpar' possíveis irregularidades eventualmente existentes em uma mídia juntada aos autos, sob pena de se substituir à parte autora e, por conseguinte, incidir em afronta ao princípio dispositivo" (TRE-PB. Representação nº 2069, Rel. Tercio Chaves de Moura, 22/01/2016). Noutro precedente, já estabilizada uma AIME, o MPE requereu a juntada de um parecer do Tribunal de Contas e o tratou como fato essencial que ampliaria o rol de causas de pedir da demanda (inicialmente com objeto mais restrito). O D. Juiz mandou excluir do thema decidendum o novo fato essencial, alegando a estabilização da demanda. $\mathrm{O}$ MPE insurgiu com a impetração de mandado de segurança, rejeitado pelo precedente com 
No julgamento da ADI em torno do art. 23 (ADI 1.082/DF), o voto do Ministro Luiz FUX esclarece o óbvio: os fatos cognoscíveis de ofício pelo Juiz Eleitoral são apenas os fatos revelados pela instrução que se relacionem com a causa de pedir já posta e exposta (e posta e exposta no prazo decadencial, parece inevitável concluir). Supor o contrário é imaginar que o controvertido art. 23 da $\mathrm{LC} \mathrm{n}^{\circ}$ 64/1990 autorizasse o magistrado a inaugurar demanda nova e, o que é mais inusitado juridicamente, fora do prazo decadencial.

Os fatos cognoscíveis de ofício são apenas os fatos simples, contíguos, instrumentais à formação da convicção necessária a julgar a demanda conformada pelas partes ${ }^{23}$. Tanto é assim que o TSE, depois do julgamento da ADI pelo Supremo que confirmou a constitucionalidade do art. 23 da LC/64, seguiu reafirmando, não por acaso, a validade da regra de estabilização da demanda. Todos os acórdãos do TSE estão no mesmo sentido:

A Corte Regional, ao condenar os recorrentes a partir de fato não alegado na inicial - extrapolação de gastos com publicidade institucional no ano do pleito - incorreu em julgamento extra petita, violan-

a seguinte fundamentação: “1. A decisão judicial está adstrita, não só ao pedido formulado na exordial, mas também à causa de pedir, que, segundo a teoria da substanciação, adotada pela legislação processual, é delimitada pelos fatos narrados na preambular. 2. Impossibilidade de ampliação da causa de pedir em momento posterior à contestação”. (TRE-PE, MS no 348227, Rel. Francisco de Queiroz Bezerra Cavalcanti, 22/10/2010).

${ }^{23}$ É como está na melhor doutrina: "É certo que o art. 23 da LC 64/90, em nome da lisura e da normalidade do processo eleitoral, faz um convite irrecusável ao magistrado de imersão total na realidade social. Tal convite não pode ser tido, a toda evidência, como atribuição de poderes instrutórios amplos e vastos aos órgãos jurisdicionais da Justiça Eleitoral, que poderiam investigar e apurar fatos estranhos ao conteúdo da petição inicial. O que o art. 23 da LC 64/90 determina, em benefício da lisura e normalidade dos prélios eleitorais, é que o magistrado não despreze, ao formar seu convencimento, nenhum fato secundário que possa ser indicativo da prática (ou da não prática) dos atos ilícitos narrados na petição inicial". (ANDRADE, 2012, p. 74). Adriano Soares da Costa também afirma que "se ao juiz é dado fundar sua decisão em fatos não alegados pelas partes, não se segue daí que sejam eles totalmente estranhos aos deduzidos na AIJE, pois não se pode deslembrar que esse remédio jurídico não tem por escopo a investigação livre de todo o prélio eleitoral, senão que apenas busca imputar a inelegibilidade cominada aos candidatos que agirem ilicitamente, ou forem beneficiados por alguma atividade dolosa. [...] Assim, adotando o legislador o princípio inquisitório extremado, deve-se compatibilizá-lo com a CF/1988, de modo a que o juiz, limitado pelo pedido da causa, apenas possa ir em busca de fatos e provas outros, contíguos aos já deduzidos, nada obstante como o direito assegurado às partes de acesso à prova produzida pelo juiz, antes que ele profira qualquer julgamento.” (COSTA, 2013, p. 385). 
do os arts. 128 e 460 do CPC (Recurso Especial Eleitoral n 42512, Rel. Min. JOÃO OTÁVIO DE NORONHA, 25/08/2014).

O Tribunal Regional incorreu em julgamento extra petita ao condenar os recorrentes por fato não descrito na petição inicial, qual seja, a suposta captação ilícita do sufrágio da eleitora Fabiana Santana. [...]. Recursos especiais parcialmente providos para afastar a condenação pela prática de captação ilícita de sufrágio [...] (Recurso Especial Eleitoral $n^{\circ}$ 3504, Rel. designado Min. GILMAR FERREIRA MENDES, 02/08/2016).

No precedente do Ministro Gilmar (unânime, no ponto), do segundo semestre de 2016, havia alegação de compra de votos, com a indicação de inúmeros eleitores. A instrução, no entanto, acabou por revelar a captação ilícita do voto de outro eleitor - não citado na inicial. É dizer: a narrativa da inicial não descrevia o fato essencial da compra de votos daquele determinado eleitor. Ou ainda: a captação que irrompeu da instrução não estava contida no episódio da vida inicialmente ventilado (PINTO, 2007). Por esse motivo não foi admitido pelo TSE, reconhecendo-se violação ao princípio da congruência.

Mesmo à luz de uma visão ampliada do alcance do art. 23, a instrução “deve servir, notadamente, para dar supedâneo, ou não, aos fatos e fundamentos jurídicos alegados e delimitados pelo autor, jamais a alterar a causa de pedir" (AMBRIZI, 2014). Toda a jurisprudência eleitoral confirma o respeito à regra da estabilização ${ }^{24}$.

\footnotetext{
24 “1. A decisão judicial está adstrita, não só ao pedido formulado na exordial, mas também à causa de pedir, que, segundo a teoria da substanciação, adotada pela legislação processual, é delimitada pelos fatos narrados na preambular. 2. Impossibilidade de ampliação da causa de pedir em momento posterior à contestação". (TRE-PE. Mandado de Segurança no 348227, Acórdão de 18/10/2010, Relator: Francisco de Queiroz Bezerra Cavalcanti, Publicação: DJE, Tomo 119, Data 22/10/2010, Página 7). "2. O julgamento da lide fora dos limites em que foi proposta - sentença extra petita - afronta os artigos 128, caput e 460, caput, do Código de Processo Civil, e contraria o princípio da congruência ou adstrição, o qual limita a atuação do juiz aos fatos expostos na petição inicial”. (TRE-GO. Agravo Regimental em Recurso no 71262, Rel.: Walter Carlos Lemes, Publicação: DJ, Volume 1, Tomo 001, Data 07/01/2014, Página 3/4). “1. A parte se defende dos fatos e não da capitulação jurídica do ato que lhe é atribuído, mas se defende dos fatos descritos na peça vestibular, não podendo ser aplicado o princípio da substanciação para introduzir ilícito não descrito na inicial, já que não se pode modificar, posteriormente, a causa de pedir, sob pena de violação aos princípios da ampla defesa e contraditório". (TRE-PA. Recurso Eleitoral no 53641, Rel.: Raimundo Holanda Reis, DJe, Tomo 106, Data 17/06/2014, Página 04).
} 


\section{Referências}

ALVIM, Frederico Franco. O litisconsórcio necessário nas ações eleitorais impugnativas. 2011. Disponível em: <https://jus.com.br/artigos/19249/o-litisconsorcio-necessario-nas-acoes-eleitorais-impugnativas >. Acesso em: 29 mar. 2017.

AMADO, Maria Elisa Padre Ataíde Ribeiro. O contencioso eleitoral no direito constitucional português. Trabalho apresentado à Comissão Nacional de Eleições. Lisboa, 1994.

AMBRIZI, Tiago Ravazzi. Fatos principais, fatos simples e fatos supervenientes. Revista de Processo, v. 39, n. 238, p. 99-126, dez. 2014.

ANDRADE, Marcelo Santiago de Pádua. Ação de impugnação de mandato eletivo. São Paulo: Manole, 2012.

BARBOSA, Edmilson. Ação de impugnação ao mandato eletivo (AIME). 2008, p. 9. Disponível em: <http://esmec.tjce.jus.br/wp-content/uploads/2008/10/acao-de-impugnacao-ao-mandato-eletivo.pdf > . Acesso em: 29 mar. 2017.

BARBOSA, Marcos Elias de Freitas. Anotações sobre a ação de impugnação de mandato eletivo. Revista de Processo, v. 17, n. 68. p. 105-110, out./dez. 1992.

BEDAQUE, José Roberto dos Santos. Efetividade do processo e técnica processual. São Paulo: Malheiros, 2006.

COSTA, Adriano Soares da. Instituições de direito eleitoral. 5. ed. Belo Horizonte: Del Rey, 2002.

Instituições de direito eleitoral. 9. ed. Belo Horizonte: Fórum, 2013.

COSTA, José Rubens. Fato superveniente. Revista dos Tribunais, São Paulo, v. 796, fev. 2002.

CRUZ E TUCCI, José Rogério. A causa petendi no processo civil. 3. ed. São Paulo: Revista dos Tribunais, 2009.

CUNHA, Leonardo Carneiro da. In: WAMBIER, Teresa Arruda Alvim; DIDIER JUNIOR, Fredie; TALAMINI, Eduardo, DANTAS, Bruno. Breves comentários ao novo código de processo civil. São Paulo: Revista dos Tribunais, 2015. p. 1.246.

DEGENSZAJN, Daniel Raichelis. Alteração dos fatos no curso do processo e os limites de modificação da causa petendi. Dissertação (Mestrado) - Universidade de São Paulo, São Paulo, 2010. 
DELGADO, Miguel S. Gil. Las garantias del derecho electoral. Revista de las Cortes Generales, n. 20, p. 109, 1990.

DÍAZ VÁSQUEZ, José Luis. Estructura política, procesos electorales y el contencioso electroal en Italia. Revista Electoral, México, v. II, n. 2, 1993, p. 2. Disponível em: <https://tecnologias-educativas.te.gob.mx/RevistaElecto$\mathrm{ral} /$ content/pdf/a-1993-01-002-078.pdf>. Acesso em: 28 mar. 2017.

DIDIER, Fredie. Parecer: ações concorrentes [...]. 2012. Disponível em: <http://www.frediedidier.com.br/wp-content/uploads/2012/02/parecer-conexao-preliminaridade.pdf.>. Acesso em: 30 mar. 2017.

DINAMARCO, Cândido Rangel. Instituições de direito processual civil. v. 3, 4. ed. São Paulo: Malheiros, 2004.

ESPINOSA, Armando Cruz. Aspectos básicos del proceso electoral. In: HERNÁNDEZ, Eduardo de Jesús Castellanos (org). Temas de derecho procesal electoral. México: Segob, 2010, p. 180.

EUROPEAN COMMISSION FOR DEMOCRACY THROUGH LAW (Venice Commission). Report on the cancellation of election result. Strasbourg, dez. 2009. p. 10. Disponível em: <http://www.venice.coe.int/ webforms $/$ documents $/$ default.aspx?pdffile $=$ CDL-AD(2009)054-e $>$. Acesso em: 28 mar. 2017.

FICHTNER, José Antônio. Impugnação de mandato eletivo. Rio de Janeiro: Renovar, 1998.

GARCIA, Emerson. Ação de impugnação de mandato eletivo. Rio de Janeiro: Lumen Juris, 2000.

GOMES, José Jairo. Direito eleitoral. 8. ed. São Paulo: Atlas, 2012.

Direito eleitoral. 12. ed. São Paulo: Atlas, 2016.

LEONEL, Ricardo Barros. Causa de pedir e pedido: o direito superveniente. São Paulo: Método, 2006.

MENDES, Antonio Carlos. Introdução à teoria das inelegibilidades. São Paulo: Malheiros, 1994.

MESSINEO, Francesco. Manual de derecho civil y comercial. Ediciones Jurídicas Europa-América, Buenos Aires, Argentina, edición a cargo de Santiago Sentís Melendo, Tomo II, Doctrinas Generales, 1971. 
MÉXICO. Tribunal Electoral del Poder Judicial de la Federación. El contencioso y la jurisprudencia electorales en derecho comparado: un estudio sobre veintiún países de América y Europa. México, 2006, p. 129. Disponível em: < http://portal.te.gob.mx/sites/default/files/publicaciones/file/contencioso.pdf>. Acesso em: 29 mar. 2017.

NIESS, Pedro Henrique Távora. Direitos políticos. Bauru: Edipro, 2000.

OROZCO, Jesús. El contencioso electoral, la calificación electoral. In: NOHLEN, Dieter; OROZCO Jesús; THOMPSON José; ZOVATTO, Daniel (comps). Tratado de derecho electoral comparado de América Latina. México: FCE, Instituto Interamericano de Derechos Humanos, Universidad de Heidelberg, International IDEA, Tribunal Electoral del Poder Judicial de la Federación, Instituto Federal Electoral, 2007. p. 1.262-1.263.

PEREIRA, Rodolfo Viana. Tutela coletiva no direito eleitoral: controle social e fiscalização das eleições. Lumen Juris, 2008, p. 74-75.

PÉREZ CORTI, José María. Derecho electoral argentino. 1. ed. Córdoba: Advocatus, 2009. p. 8. Disponível em: <http://www.joseperezcorti.com.ar/ Archivos/Postgrados/UNSAM_Escuela_de_Politica_y_Gobierno/Unidades_Perez_Corti/U9_Derecho_Procesal_Electoral_UNSAM_20100918. pdf $>$. Acesso em: 28 mar. 2017.

PINTO, Junior Alexandre Moreira. A causa petendi e o contraditório. São Paulo: Revista dos Tribunais, 2007.

PINTO JUNIOR, Amaury Rodrigues. A estabilização da demanda e o direito superveniente. Revista de Processo, v. 39, n. 227, p. 87-103, jan. 2014.

PORTO, Sérgio Gilberto. Comentários ao código de processo civil. São Paulo. Revista dos Tribunais, 2000.

SALGADO, Eneida Desiree; VALIATI, Thiago Priess; BENARDELLI, Paula. O livre convencimento do juiz eleitoral versus fundamentação analítica exigida pelo novo Código de Processo Civil. In: TAVARES, André Ramos et al (Coord.). O direito eleitoral e o novo código de processo civil. 1. ed. Belo Horizonte: Fórum, 2016. p. 355-357.

SANTOS, Antônio Augusto Mayer dos. Da ação de impugnação de mandato eletivo: histórico evolutivo e síntese procedimental. Revista Paraná Eleitoral, n. 28, 1998. p. 5. Disponível em: <http://www.justicaeleitoral. jus.br/arquivos/tre-pr-revista-parana-eleitoral-n028-1998-antonio-augusto-mayer-dos-santos>. Acesso em: 28 mar. 2017. 
SCARPINELLA BUENO, Cassio. In: MARCATO, Antonio Carlos (Coord.). Código de processo civil interpretado. São Paulo: Atlas, 2004, p. 1.422.

SERRANO, María Camila García. Acción de nulidad electoral: principio democrático vs. derechos del elegido. Disertación (Magister en Derecho) Facultad de Derecho, Ciencias Políticas y Sociales, Universidad Nacional de Colombia, Bogotá, 2014.

SILVA, Daniel Monteiro. Ação de Impugnação de Mandato Eletivo: análise constitucional e novas perspectivas. 185 f. Dissertação Mestrado em Constituição e Garantias de Direitos) - Universidade Federal do Rio Grande do Norte. Natal: 2010.

UNITED KINGDOM. The electoral comission. challenging elections in the UK. set. 2012. Disponível em: < http://www.electoralcommission.org. uk/_data/assets/pdf_file/0010/150499/Challenging-elections-in-the-UK. pdf>. Acesso em: 28 mar. 2017.

URUGUAY. Ley de elecciones. Ley n⿳ำ 7.812, del 16 de enero de 1925, modificada por Ley $\mathrm{n}^{\circ}$ 17.113, de 9 de junio de 1999.

VESCOVI, Enrique. La modificación de la demanda. Revista de Processo, v. 8, n. 30, p. 206-212, abr./jun., 1986.

VIANA, Juvêncio Vasconcelos. A causa de pedir nas ações de execução. In: CRUZ E TUCCI, José Rogério; BEDAQUE, José Roberto dos Santos (Coord.). Causa de pedir e pedido no processo civil: questões polêmicas. São Paulo: Revista dos Tribunais, 2002. p. 97.

VIEIRA, Luíta Maria Ourém Sabóia. O princípio da correlação aplicado ao processo civil e ao processo penal. Revista de Processo, v. 37, n. 211, p. 391-415, set. 2012.

WAMBIER, Teresa Arruda Alvim. Nulidades da sentença. 3. ed. São Paulo: Revista dos Tribunais, 1996.

; DIDIER JUNIOR, Fredie; TALAMINI, Eduardo, DANTAS, Bruno. Breves comentários ao novo código de processo civil. São Paulo: RT, 2015. p. 1.246.

Luiz Fernando Casagrande Pereira - Mestre e Doutor em Direito pela UFPR (processo civil). Autor de diversos livros e artigos publicados nas áreas de processo civil e eleitoral. Professor e palestrante de inúmeras instituições nas áreas de concentração. Coordenador da pós-graduação de Direito Eleitoral da Universidade Positivo. Presidiu o V Congresso Brasileiro de Direito Eleitoral - Curitiba, 2016. 
